\title{
Stimulation Calculation of Desulfurization
}

Mechanisms Dominated by Free Radicals Reactions During Pyrolysis of Thiophenes Under Water Vapor Atmosphere

\author{
Ya Cheng \\ Inner Mongolia University \\ Jianping Chen \\ Inner Mongolia Medical University \\ Huiqing Guo \\ Inner Mongolia Medical University \\ Yanqiu Lei \\ Inner Mongolia University \\ Fenrong Liu ( $\nabla$ fenrongl@163.com ) \\ Inner Mongolia University
}

\section{Research Article}

Keywords: Desulfurization mechanism, Steam atmosphere, Thiophene compounds, Pyrolysis, Free radicals

Posted Date: August 20th, 2021

DOI: https://doi.org/10.21203/rs.3.rs-825741/v1

License: (c) (i) This work is licensed under a Creative Commons Attribution 4.0 International License.

Read Full License 
2 free radicals reactions during pyrolysis of thiophenes under water

\section{vapor atmosphere}

\author{
Ya Chenga ${ }^{a}$, Jianping Chen ${ }^{b}$, Huiqing Guo ${ }^{b^{*}}$, Yanqiu Lei ${ }^{a}$ and Fenrong Liu ${ }^{a^{*}}$

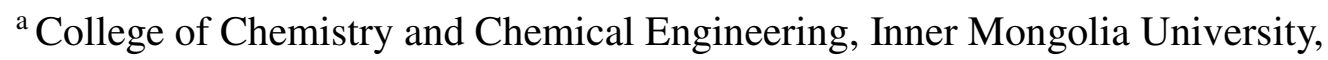 \\ Hohhot 010021, China
}
${ }^{\mathrm{b}}$ School of Pharmaceutical Science, Inner Mongolia Medical University, Hohhot 010110, China

*Corresponding author. Phone/Fax: +86-471-4992981. E-mail: fenrong1@163.com, gvohq@immu.edu.cn Ya Cheng and Jianping Chen contributed equally to this work.

Abstract: The desulfurization mechanisms of thiophene and 2-methyl thiophene were investigated by the density functional theory (DFT) during pyrolysis under water vapor atmosphere. All possible reaction pathways of these desulfurization mechanisms were explored at M06-2X/6-311g (d) level. The Multwfn3.0 and VMD1.9.2 programs were used to analyze weak interactions between thiophene compounds and $\mathrm{H}_{2} \mathrm{O}$ molecule. It can be seen that hydrogen bonds can be formed in the reactions of thiophene sulfurs and $\mathrm{H}_{2} \mathrm{O}$. Since $\mathrm{H}_{2} \mathrm{O}$ molecule can decompose at higher temperature and generate free radicals, such as $\bullet \mathrm{H}$ and $\bullet \mathrm{OH}$, the desulfurization mechanisms of thiophene and 2-methyl thiophene with free radicals need to be further considered. The reaction energy barriers $\left(\Delta G^{\ddagger}\right)$ and reaction energies $\left(\Delta G_{\mathrm{P}}\right)$ of thiophene and 2-methyl thiophene with $\mathrm{H}_{2} \mathrm{O}$ molecule (g) or free radicals $(\cdot \mathrm{H}$ and $\bullet \mathrm{OH})$ 
have been stimulated and calculated in detail. Based on the transition state theory (TST), the rate constants corresponding to these elementary reactions are also calculated, meanwhile the speed and spontaneity of every reaction can be obtained from the aspect of kinetics. Theoretically, it is found that $\mathrm{H}_{2} \mathrm{O}(\mathrm{g})$ directly attacking C-S bonds of thiophene and 2-methyl thiophene cannot easily generate COS and $\mathrm{H}_{2} \mathrm{~S}$ even at $1200 \mathrm{~K}$ in terms of thermodynamics and kinetics. If the desulfurization mechanisms of thiophenes are investigated by free radicals mechanisms under steam atmosphere, their initial energy barriers needing to be overcome significantly reduce. Therefore, desulfurization mechanisms of thiophenes and $\mathrm{H}_{2} \mathrm{O}(\mathrm{g})$ are the most possibly dominated by radical reactions at higher temperatures and $\mathrm{H}_{2} \mathrm{~S}$ is mainly generated.

Keywords: Desulfurization mechanism; Steam atmosphere; Thiophene compounds; Pyrolysis; Free radicals

\section{Introduction}

China consumes the most coal worldwide. The sulfur and nitrogen heteroatoms in coal would be converted to sulfur-containing gases $\left(\mathrm{COS}, \mathrm{H}_{2} \mathrm{~S}, \mathrm{SO}_{\mathrm{X}}\right)$ and nitrogen oxides $\left(\mathrm{NO}_{\mathrm{X}}\right)^{1}$. Thus, massive utilization of coal can cause various environmental issues, such as air pollution and acid rain. Therefore, Sulfur removal before the toxic sulfur compounds are released into the environment is also an important subject ${ }^{2}$.

Hydrous pyrolysis was used to simulate desulfurization reaction and the obtained data suggest that water acts like a reactant ${ }^{3}$. But, the detailed desulfurization mechanism under steam atmosphere remains unclear ${ }^{4}$. Aliphatic sulfur compounds, 
such as thiols and sulfides, have been found to react during the experiment of hydrothermal simulation in 473-603K. Liu et al. ${ }^{3}$ found that the increasing of the feed ratio of water to thiophene facilitates desulfurization and more gases were generated. Abraham and Klein ${ }^{5}$ investigated the reaction of benzylphenyl sulfide (BPS) in subcritical water and observed benzaldehyde as the major product, indicating that water was involved as a reactant. Thus, water vapor has been used as an atmosphere to investigate desulfurization behavior during coal pyrolysis. As large quantities of $\mathrm{H}_{2}$ and expensive catalysts were required during the conventional hydro desulfurization process, water vapor pyrolysis can be considered as a potential alternative desulfurization method to reduce sulfur content in high sulfur coals. Water vapor attacks C-S bond of thiophene which results in the breakage of the C-S bond, and $\mathrm{H}_{2} \mathrm{~S}$, $\mathrm{CO}, \mathrm{CO}_{2}, \mathrm{H}_{2}$, light hydrocarbons and other gases are produced during the hydrothermal cracking of thiophene ${ }^{6,7,8}$. Under steam atmosphere, $\mathrm{H}$ and $\mathrm{OH}$ free radicals are easily formed at high temperature. Wang et al. ${ }^{9}$ has focused on the effect of steam on the transformation of sulfur during coal pyrolysis at the range of temperatures from 573 to 1073K. The removal of organic sulfur was found to increase, because the addition of steam above $773 \mathrm{~K}$ promoted the decomposition of thiophenic sulfur. In addition, steam can generate more $\cdot \mathrm{H}$ radicals, promoting the formation of $\mathrm{H}_{2} \mathrm{~S}^{9}$.

There have been several experimental studies about the desulfurization behaviors $10,11,12$, but few have focused on the detailed desulfurization mechanism at the micro level. Quantum chemistry can be used to calculate the thermochemical properties of coal, the interaction between coal surface and gas, the desulfurization mechanism of 
67 sulfur-containing model compounds and their pyrolysis reactions ${ }^{13,14,15,16}$. It can also help explaining some unclear phenomena in the experiments at a theoretical level. Yuko Kida et al. ${ }^{9}$ used quantum chemistry to calculate the radical reactions of C-S bond cleavage in hexyl sulfide and the addition of water to the $\mathrm{C}=\mathrm{S}$ bond to form a geminal mercaptoalcohol in the supercritical water (SCW) experiment. The mercaptoalcohol then decomposes into an aldehyde and $\mathrm{H}_{2} \mathrm{~S}$ either directly or via a water-catalyzed 6-membered ring transition state. So their results showed that $\mathrm{H}_{2} \mathrm{O}$ is a reactant and can participate in the decomposition reaction of hexyl sulfide. Other theoretical studies have also shown $\mathrm{H}_{2} \mathrm{O}$ can reduce the energy barrier of gas phase single molecular reactions in several systems ${ }^{17,18,19}$. In recent years, interactions between water molecules and coal models have been extensively studied ${ }^{20,21,22}$. Water molecules tend to accumulate around oxygen-containing functional groups of coal models and hydrogen bonds play a leading role in the interaction according to the Reduced Density Gradient (RDG) analysis ${ }^{23}$.

Because of the variably complicated three-dimensional macromolecular structure of coal, it is difficult to build coal itself via modeling tools. The homolytic energy of monocyclic aromatic compounds often can be used to predict the homolytic energy of polycyclic aromatic compounds with similar structures. Thus, in this study, thiophene and 2-methyl thiophene were selected to represent the difficult-to-remove coal-based sulfur species and to investigate their detailed desulfurization mechanisms during pyrolysis under steam atmosphere. All possible desulfurization pathways of these thiophenes were calculated and analyzed from the perspective of thermodynamics and 
kinetics. Therefore, the detailed desulfurization mechanisms of these thiophenes can be obtained under steam atmosphere. This can provide some theoretical basis for coal desulfurization during coal utilization under steam atmosphere.

\section{Calculation methods}

\subsection{Geometry optimization and energy evaluation}

All quantum chemistry calculations were carried out using the Gaussian 09 software package $^{24}$. Geometry optimization of various reactants, products, intermediate (IMn) and transition states (TSn) were calculated by using the mixed element exchange correlation function M06-2X $\mathrm{X}^{25,26}$ with the standard base group 6-311g(d) in density fun ctional theory (DFT), and the thermodynamic correction was calculated at the same theoretical level. M06-2X with Grimme's DFT-D3 dispersion correction using the Becke-Johnson damping function is highly suitable and reliable for noncovalent interaction calculations ${ }^{27,28}$. Moreover, for each transition state calculations of intrinsic reaction coordinate (IRC) and vibration analysis, using a same basis set for computational rationality (M06-2X/6-311g(d)), were used to confirm the connections between the reactants and products correspondingly. The transition state has only one imaginary frequency ${ }^{18,29,30}$, and all other species have real frequency. M06-2X/def2tzvp was used to calculate the single point energy which was added to the thermodynamic correction amount to obtain the energy barrier $\left(\Delta G^{\neq}\right)$of each step reaction. Reaction energy $\left(\Delta G_{\mathrm{P}}\right)$ was used to judge whether the reaction is spontaneous. All relative energy barrier $\left(\Delta G^{\ddagger}\right)$ and reaction energy $\left(\Delta G_{\mathrm{P}}\right)$ were obtained via equations (1) and (2) 


$$
\Delta G_{\mathrm{P}}=G_{\mathrm{P}}-G_{\mathrm{R}}
$$

where $G_{P}, G_{R}, G_{T S}, G_{I M}$ are the Gibbs free energy of the corresponding product $(P)$, reactant (R), transition state (TSn) and intermediate (IMn) of a pathway, respectively.

\subsection{The Reduced Density Gradient (RDG) Analysis} function, and the points in space and the sign $[\lambda 2(\mathrm{r})] \rho(\mathrm{r})$ function were used as coordinates to make a RDG diagram by the wave function program Multiwfn3.4.1 ${ }^{32}$ and the visualization program VMD1.9.2 $2^{33}$. The RDG diagram can manifest weak interaction areas between molecules and inter molecules. The smaller value $\left[\lambda_{2}(r)\right] \rho(r)$ of the scatter $\left(\rho>0, \lambda_{2}<0\right)$ indicates that the interaction is of stronger attractive (H-bonds). The higher sign $\left[\lambda_{2}(r)\right] \rho(r)$ of the scatter $\left(\rho>0, \lambda_{2}>0\right)$ indicates that the interaction is a repulsive force. If the sign $\left[\lambda_{2}(r)\right] \rho(r)$ of the scatter is close to zero $(\rho \approx 0$, $\lambda_{2} \approx 0$ ), this interaction is Van der Waals (vdW) forces. The complex structures of thiophene sulfurs and $\mathrm{H}_{2} \mathrm{O}$ have been optimized at the M06-2X/6-311g (d) level and used for RDG analysis. The RDG function equation is

$$
\operatorname{RDG}(\mathrm{r})=\frac{1}{2\left(3 \pi^{2}\right)^{1 / 2}} \frac{|\nabla \rho(\mathrm{r})|}{\rho(\mathrm{r})^{4 / 3}}
$$
where $\rho(r)$ is the electron density varing with $\mathrm{r}$.

\subsection{Reaction rate constant calculation}

The rate constants of reactions of thiophene sulfurs and water vapor can be obtained according to the following equation ${ }^{34}$, 


$$
\mathrm{k}(T)=\frac{K_{B} T}{h}\left(\frac{Q_{T S}}{Q_{R}}\right) \exp \left(-\frac{E_{a}}{K_{B} T}\right)
$$

where $\mathrm{K}_{\mathrm{B}}$, T, and Ea are the Boltzmann constant, reaction temperature (298 K), and activation energy, respectively. $\mathrm{Q}_{\mathrm{TS}}$ and $\mathrm{Q}_{\mathrm{R}}$ are the partition functions per unit volume for a TS and a reactant, respectively.

\section{Results and discussion}

In this study, thiophene $\left.\left({ }_{4}^{5} \pi^{\frac{1}{5}}\right\rangle_{3}^{2}\right)$, 2-methyl thiophene $\left.\left({ }_{4}^{6} 4^{5}\right\rangle_{3}^{1}\right)$ were selected to investigate their desulfurization mechanisms during pyrolysis under steam atmosphere.

During pyrolysis, water vapor maybe directly attack C-S bonds, or water vapor dissociates and forms free radicals $(\cdot \mathrm{H}$ and $\bullet \mathrm{OH})$. Free radicals then attack $\mathrm{C}-\mathrm{S}$ bonds or / and other carbon sites, and $\mathrm{H}_{2} \mathrm{~S}, \mathrm{CO}, \mathrm{H}_{2}$, light hydrocarbons and other gases could be generated [3]. Therefore, we aim to investigate the addition reactions $\mathrm{of}_{2} \mathrm{O}$ and C-S bonds of thiophene sulfurs and radical reactions of free radicals and thiophenes and obtained the most possible desulfurization mechanisms of thiophenes and $\mathrm{H}_{2} \mathrm{O}$.

\subsection{RDG analysis of thiophenes and $\mathrm{H}_{2} \mathrm{O}$}

Fig. 1 shows the RDG diagrams of complexes (i.e., A and B) formed by two typical thiophenes with $\mathrm{H}_{2} \mathrm{O}(\mathrm{g})$. The RDG diagram of complex $\mathrm{A}$ is of thiophene and $\mathrm{H}_{2} \mathrm{O}$ (g). The large green or brown-green isosurface indicates that the weak vdW interaction in complex $\mathrm{A}$ is quite obvious, corresponding to the spikes at the scattered value range from -0.01 a.u. to 0.01 a.u. The fusiform red isosurface in the thiophene ring indicates that the ring itself has spatial repulsion (see the spike at the range from 0.035 a.u. to 0.040 a.u.).

The RDG diagram of complex $\mathrm{B}$ is of $\mathrm{H}_{2} \mathrm{O}$ and 2-methyl thiophene. For complex $\mathrm{B}$, 
154

155

156

157

158

159

160

161

162

163

164

165

166

167

168

169

170

171

172

173

$\mathrm{S}$ atom of 2-methyl thiophene and $\mathrm{H}$ atom of $\mathrm{H}_{2} \mathrm{O}$ can form distinct $\mathrm{H}$-bond at the scattered value of -0.040 a.u. to -0.035 a.u., and there also is a large spatial repulsive force between $\mathrm{O}$ in $\mathrm{H}_{2} \mathrm{O}$ and $\mathrm{C} 5$ on 2-methylthiophene, corresponding to the spikes at the value ranging from 0.020 a.u. to 0.030 a.u..

\subsection{Desulfurization mechanisms of thiophenes with $\mathrm{H}_{2} \mathrm{O}(\mathrm{g})$ addition reactions}

Recently, for the better desulfurization effect and higher tar yield of coal, the supplement of hydrogen source is the most effective method. Water vapor used for pyrolysis desulfurization is a relative cheap and easily available hydrogen source. Thus, in order to investigate the effect of water molecules on desulfurization mechanisms, the reaction mechanisms of $\mathrm{H}_{2} \mathrm{O}(\mathrm{g})$ or free radicals $(\bullet \mathrm{H}$ and $\bullet \mathrm{OH})$ with thiophenes were calculated and investigated. The most possible pathways of thiophenes and $\mathrm{H}_{2} \mathrm{O}(\mathrm{g})$ are considered as follows:
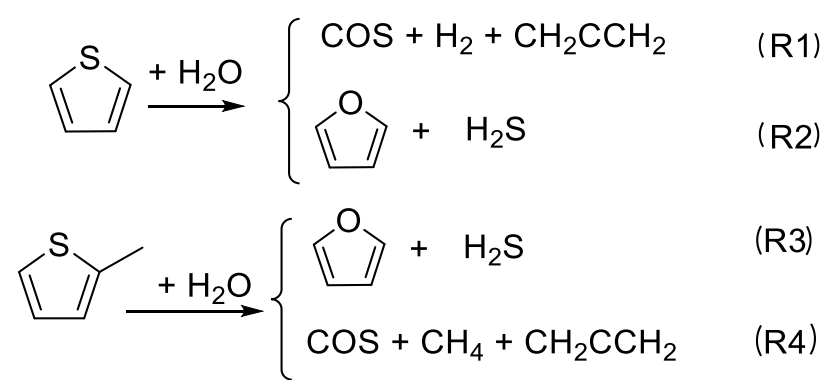

\subsubsection{Desulfurization mechanisms of thiophenes with $\mathrm{H}_{2} \mathrm{O}$}

Fig. 2 illustrates the energy diagrams of thiophene and $\mathrm{H}_{2} \mathrm{O}$ forming $\mathrm{COS}(\mathrm{R} 1)$ and $\mathrm{H}_{2} \mathrm{~S}$ (R2) at $1200 \mathrm{~K}$. For R1, $\mathrm{H}_{2} \mathrm{O}$ firstly attacks $\mathrm{C} 2$ site in thiophene and forms intermediate IM1 by overcoming the energy barrier $(145.6 \mathrm{kcal} / \mathrm{mol})$ of $\mathrm{TS} 1$, meanwhile one molecule of $\mathrm{H}_{2}$ is removed. Then, IM2 is formed through TS2 after overcoming a $64.9 \mathrm{kcal} / \mathrm{mol}$ energy barrier. Subsequently, H migration occurs from C4 to C5 in IM2 and then IM3 is generated. Lastly, C-S, C-C bonds of IM3 are 
broken, and $\mathrm{COS}, \mathrm{H}_{2}$ and $\mathrm{CH}_{2} \mathrm{CCH}_{2}$ are generated. In $\mathrm{R} 2$, the $\mathrm{H} \cdots \mathrm{OH}$ bond in $\mathrm{H}_{2} \mathrm{O}$ is extended from the original $0.97 \AA$ to $1.02 \AA$ by the transition state TS 1 and is added to the C-S bond of thiophene to form intermediate IM1. Then, H migration in IM1 occurs after overcoming a $46.6 \mathrm{kcal} / \mathrm{mol}$ barrier and IM2 is formed. Lastly, IM2 undergoes the closed-loop reaction and forms furan, meanwhile one molecular $\mathrm{H}_{2} \mathrm{~S}$ is removed. Thermodynamically and dynamically, $\mathrm{H}_{2} \mathrm{O}(\mathrm{g})$ attacking $\mathrm{C}-\mathrm{S}$ bonds of thiophene cannot easily generate $\mathrm{COS}$ and $\mathrm{H}_{2} \mathrm{~S}$ at $1200 \mathrm{~K}$, as the $\Delta G_{\mathrm{P}}$ of $\mathrm{R} 1$ and $\mathrm{R} 2$ are $2.8 \mathrm{kcal} / \mathrm{mol}$ and $11.8 \mathrm{kcal} / \mathrm{mol}$, respectively.

Fig. 3 is the energy diagram of 2-methyl thiophene and $\mathrm{H}_{2} \mathrm{O}(\mathrm{g})$ forming $\mathrm{H}_{2} \mathrm{~S}(\mathrm{R} 3)$ and COS (R4) at $1200 \mathrm{~K}$. In R3 and R4, the formation of their IM1s needs to overcome the higher initial reaction energy barriers of $116.3 \mathrm{kcal} / \mathrm{mol}$ and 147.3 kcal/mol, respectively. For R3, IM1 undergoes an closed-loop reaction and intramolecular hydrogen migration and C-S bonds cleavage to form 2-methylfuran and $\mathrm{H}_{2} \mathrm{~S}$. The $\Delta G_{\mathrm{P}}$ of R3 is $3.9 \mathrm{kcal} / \mathrm{mol}$. IM1 in R4 undergoes two-step H migration and IM3 is generated. Then, C-S, C-C bonds of IM3 are broken and $\mathrm{COS}, \mathrm{CH}_{4}$ and $\mathrm{CH}_{2} \mathrm{CCH}_{2}$ are generated. $\mathrm{R} 3$ are thermodynamically non-spontaneous. Although reaction $\mathrm{R} 4\left(\Delta G_{\mathrm{P}}=-13.4 \mathrm{kcal} / \mathrm{mol}\right)$ is thermodynamically spontaneous, it needs to overcome a very high energy barrier. Thus, it is also not easy to generate $\mathrm{H}_{2} \mathrm{~S}$ and COS at $1200 \mathrm{~K}$ for $\mathrm{H}_{2} \mathrm{O}$ with thiophene and 2-methyl thiophene through $\mathrm{R} 3$ and $\mathrm{R} 4$.

\subsubsection{Desulfurization mechanisms of thiophenes with free radicals $(\cdot \mathbf{H}$ and $\bullet \mathbf{O H}$ )}

Free radicals play a crucial role in coal pyrolysis process ${ }^{35} . \mathrm{H}$ and $\mathrm{OH}$ free radicals generation, stabilization and condensation easily occur during water vapor treatment 
and coal pyrolysis progress ${ }^{36,37}$. The removal of organic sulfur was found to increase, because the addition of steam results in generating more $\mathrm{H}$ free radicals promoting the generation of $\mathrm{H}_{2} \mathrm{~S}^{9}$. Based on these results, desulfurization reactions of thiophenes with free radicals $(\cdot \mathrm{H}$ and $\cdot \mathrm{OH})$ were proposed and investigated under steam atmosphere. The possible desulfurization pathways of thiophene, 2-methyl thiophene and free radicals are considered as follows:
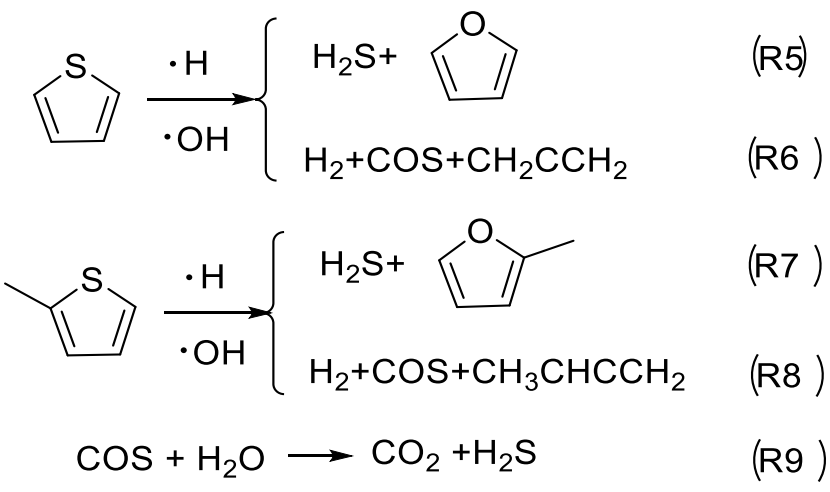

Fig. 4 shows energy diagrams of thiophene and $\bullet \mathrm{H}$ and $\bullet \mathrm{OH}$ forming $\mathrm{H}_{2} \mathrm{~S}$ (R5) and COS (R6) at $1200 \mathrm{~K} . \mathrm{H}$ and $\mathrm{OH}$ radicals are mainly derived from the decomposition of water vapor [36] and coal [37]. For R5, firstly, $\mathrm{H}$ radical is adsorbed on the C2 site of thiophene, and the unstable cyclic thiophene radical $(\mathrm{R})$ is formed after overcoming a $1.9 \mathrm{kcal} / \mathrm{mol}$ energy barrier. Then, $\mathrm{OH}$ radical combines with the $\mathrm{C} 5$ site in $\mathrm{R}$ with only a $41.7 \mathrm{kcal} / \mathrm{mol}$ barrier and IM1 is generated. Subsequently, IM3 is formed by two steps of hydrogen transferring. Lastly, IM3 transforms into $\mathrm{H}_{2} \mathrm{~S}$ and furan through C-S bond breakage with a low energy barrier of $20.2 \mathrm{kcal} / \mathrm{mol}$. For R6, the energy barrier of transition state from IM1 to IM2 $(80.3 \mathrm{kcal} / \mathrm{mol})$ is very high. Then, IM2 undergoes $\mathrm{H}$ migrations from $\mathrm{C} 3$ site to $\mathrm{C} 4$ site and IM3 is formed through overcoming an energy barrier of $72.8 \mathrm{kcal} / \mathrm{mol}$. Lastly, $\mathrm{COS}, \mathrm{H}_{2}$ and $\mathrm{CH}_{2} \mathrm{CCH}_{2}$ are 
formed by C-C and C-S bonds cleavage of IM3. As of its high energy barrier, it is also impossible for $\mathrm{R} 6$ to occur. Thus, $\mathrm{H}_{2} \mathrm{~S}$ is the main product during thiophene desulfurization under steam atmosphere. Compared with the reactions of thiophene with $\mathrm{H}_{2} \mathrm{O}$, its desulfurization mechanism should be dominated by radical reactions at high temperatures in water vapor atmosphere. These results can further prove that the hydrogen radicals significantly reduce the energy barrier of thiophene desulfurization reaction. The reason is that $\cdot \mathrm{H}$ can damage the aromaticity of thiophene according to the anisotropy of the induced current density (ACID) analysis [15] to form unstable complex cyclic thiophene radical (R).

Fig. 5 lists the energy diagrams of 2-methyl thiophene with $\bullet \mathrm{H}$ and $\bullet \mathrm{OH}$ forming $\mathrm{H}_{2} \mathrm{~S}(\mathrm{R} 7)$ and COS (R8) at $1200 \mathrm{~K}$. For R7 and R8, dynamically, • H firstly combines with C2 or C5 sites of 2-methyl thiophene to form 2-methyl thiophene radical (R) by overcoming only a 8.0 or $3.1 \mathrm{kcal} / \mathrm{mol}$ energy barrier, respectively. And this energy barrier is lower than the total reactants energy of 2-methyl thiophene and $\cdot \mathrm{H}$. $\mathrm{OH}$ radical then attacks $\mathrm{C} 5$ or $\mathrm{C} 2$ sites to form a complex IM1 after overcoming the energy barrier of 45.0 or $47.6 \mathrm{kcal} / \mathrm{mol}$, respectively. IM1 in R7 undergoes two-step H migration and IM3 is generated. Then, a closed-loop reaction occurs and a molecule of $\mathrm{H}_{2} \mathrm{~S}$ is removed through TS4 to form $\mathrm{H}_{2} \mathrm{~S}$ and 2-methyl furan after overcoming a low energy barrier of $23.8 \mathrm{kcal} / \mathrm{mol}$. For R8, IM1 undergoes similar reaction steps as R6 and generates $\mathrm{COS}, \mathrm{H}_{2}$ and $\mathrm{CH}_{3} \mathrm{CHCCH}_{2}$. These calculated results show that thiophenes reacting with $\bullet \mathrm{H}$ and $\cdot \mathrm{OH}$ can generate $\mathrm{COS}, \mathrm{H}_{2} \mathrm{~S}$ and small molecular hydrocarbons. But, COS is unstable compared with $\mathrm{H}_{2} \mathrm{~S}^{38}$, as it can be converted to 
$\mathrm{H}_{2} \mathrm{~S}$ (R9) in steam atmosphere in the reactor ${ }^{39}$. Consistent with some previous experimental conclusions, sulfur-containing gases are mainly $\mathrm{H}_{2} \mathrm{~S}$ during pyrolysis of thiophenes in water vapor system ${ }^{3,9}$. Therefore, at higher temperatures, thiophenes desulfurization mechanisms are most likely dominated by radical reactions under steam atmosphere.

\subsection{Rate constant analysis}

In order to investigate the effect of reaction temperatures and $\mathrm{H}_{2} \mathrm{O}(\mathrm{g}) /$ radicals on desulfurization mechanisms of thiophene and 2-methyl thiophene, the reaction rate constant of each path was calculated between $700 \mathrm{~K}-1200 \mathrm{~K}$ by transition state theory ${ }^{39}$ (TST) and listed in Table 1. R1, R2 and R3 are thermodynamically unfeasible even at $1200 \mathrm{~K}$, so their reaction rate constants are not considered. As shown in Table 1, R4 is the reaction path of thiophene sulfur and $\mathrm{H}_{2} \mathrm{O}(\mathrm{g})$ for forming COS. $\mathrm{R} 5$ and $\mathrm{R} 7$ are the paths of thiophene and 2-methyl thiophene with free radicals for generating $\mathrm{H}_{2} \mathrm{~S}$, respectively. R6 and R8 are the paths of thiophene and 2-methyl thiophene with free radicals to generate COS, respectively. All these rate constants increase with the increasing of the reaction temperatures from $700 \mathrm{~K}$ and $1200 \mathrm{~K}$. The rate constants rank of generating $\mathrm{H}_{2} \mathrm{~S}$ and $\mathrm{COS}$ is: $k[\mathrm{R} 7]>\mathrm{k}[\mathrm{R} 5]>\mathrm{k}[\mathrm{R} 6]>\mathrm{k}[\mathrm{R} 8]>\mathrm{k}[\mathrm{R} 4]$ at $1200 \mathrm{~K}$. For $\mathrm{R} 5$ (R7), the rate constant for generating $\mathrm{H}_{2} \mathrm{~S}$ is higher about $10-10^{3}$ times than that of COS (R6 and R8) at 1200K. This further indicates that the sulfur-containing gases generated by the reaction of thiophenes and free radicals are mainly $\mathrm{H}_{2} \mathrm{~S}$. The rate constants of COS formation in R6 and R8 are about $3 \times 10^{10}$ times higher than that of 
$\mathrm{R} 4$ at $1200 \mathrm{~K}$. This further proves that $\cdot \mathrm{OH} / \cdot \mathrm{H}$ participation is more beneficial for $\mathrm{COS}$ formation than $\mathrm{H}_{2} \mathrm{O}(\mathrm{g})$ during thiophenes desulfurization.

\section{Conclusions}

The desulfurization mechanisms of thiophene and 2-methyl thiophene under steam atmosphere have been investigated in detail. The following conclusions can be drawn: $\mathrm{H}_{2} \mathrm{O}$ attacking C-S bond of thiophene and 2-methyl thiophene cannot kinetically and thermodynamically form $\mathrm{H}_{2} \mathrm{~S}$ and $\mathrm{COS}$ even at $1200 \mathrm{~K}$, as their higher reaction energy barriers need to be overcome. The reaction energies of these thiophenes with free radicals can reduce significantly compared with $\mathrm{H}_{2} \mathrm{O}$ molecule.

At higher temperature, thiophenes and free radicals can kinetically and thermodynamically react and form $\mathrm{H}_{2} \mathrm{~S}$ and COS. And $\mathrm{H}_{2} \mathrm{~S}$ is the main sulfur-containing gases, its rate constant further proves that rate of generating $\mathrm{H}_{2} \mathrm{~S}$ is faster than COS. Therefore, the most possible mechanisms for the removal of thiophenes are dominated by free radical reaction mechanisms in water vapor atmosphere at high temperatures. This can provide some theoretical basis for the desulfurization mechanisms of sulfurs in coals during pyrolysis.

\section{Acknowledgements}

This study was financially supported by the Projects of Natural Science Foundation of China (No. 21865018) and the Project Natural Science Foundation of Inner Mongolia (No. 2018MS02005). We also thank Dr. Sobereva for his enlightening advice on DFT calculations.

\section{References}


1. Liu, J. et al. Theoretical study of the effect of hydrogen radicals on the formation of HCN from pyrrole pyrolysis. J. Energy Inst. 92,1468-1475(2019).

2. Liu, F. et al. Py-MS study of sulfur behavior during pyrolysis of high-sulfur coals under different atmospheres. Fuel Processing Technology;91,1486-1490 (2010).

3. Liu, Y. et al. Equilibrium calculation of thiophene hyodropyrolysis and reaction mechanism analysis. Journal of Chemical Industry and Engineering 56,6-10 (2005). (in Chinese)

4. Vogelaar, B. M. et al. Applicability of supercritical water as a reaction medium for desulfurisation and demetallisation of gasoil. Fuel Process. Technol. 61,265-277(1999).

5. Abraham, M. A. et al. Reactions of benzyl phenyl sulfide neat and in dense polar solvents. Fuel Sci. Technol. Int. 6,633-662(1988).

6. Clark, P. D. et al. Chemistry of organosulphur compound types occurring in heavy oil sands 1. High temperature hydrolysis and thermolysis of tetrahydrothiophene in relation to steam stimulation processes. Fuel. 62,959-962(1983).

7. Clark, P. D. et al. Some chemistry of organosulphur compound types occurring in heavy oil sands 2. Influence of $\mathrm{pH}$ on the high temperature hydrolysis of tetrahydrothiophene and thiophene. Fuel. 63,125-128(1984).

8. Clark, P. D. et al. Chemistry of organosulphur compound types occurring in heavy oil sands 3 . Reaction of thiophene and tetrahydrothiophene with vanadyl and nickel salts. Fuel. 63,1649-1654(1984). 
9. Wang, M. et al. Effect of steam on the transformation of sulfur during demineralized coal pyrolysis. J. Anal. Appl. Pyrolysis. 140,161-169(2019).

10. Yang, N. et al. Effects of atmospheres on sulfur release and its transformation behavior during coal thermolysis. Fuel. 215,446-453(2018;).

11. Shao, D. et al. Behavior of sulfur during coal pyrolysis. J. Anal. Appl. Pyrolysis. 30,91-100(1994).

12. Yan J. et al. SH Radical: The key intermediate in sulfur transformation during thermal processing of coal. Environ. Sci. Technol. 2005;39,5043-5051.

13. Gao, Z, et al. Adsorption mechanism of lignite and water molecules. Journal of China Coal Society. 42,505-511 (2017). (in Chinese)

14. Nguyen, T. L. et al. Theoretical study of reaction of ketene with water in the gas phase: formation of acetic acid? J. Phys. Chem. A. 117,10997-11005(2013).

15. Zhang, F. et al. Theoretical study on desulfurization mechanisms of a coal-based model compound 2-methylthiophene during pyrolysis under inert and oxidative atmospheres. Fuel. 257,1-9(2019).

16. Li, T. et al. DFT research on benzothiophene pyrolysis reaction mechanism. J. Phys. Chem. A. 123:796-810(2019).

17. He, F. et al. Quantum chemistry calculations on the mechanism of isoquinoline ring-opening and denitrogenation in supercritical water. Ind. Eng. Chem. Res. $56,1782-1790(2017)$

18. Hazra, M. K. Sinha A. Formic acid catalyzed hydrolysis of SO3 in the gas phase: a barrierless mechanism for sulfuric acid production of potential atmospheric 
19. Zhang, Y. et al. Decomposition of formic acid in supercritical water. Energy Fuels. 24,95-99(2010).

20. Gao, Z. et al. Micro-mechanism of water molecule adsorption on lignite surfaces. Journal of Chinese Society of Power Engineering 36,258-264(2016). (in Chinese)

25. Zhao, Y. Truhlar DG. The M06 suite of density functionals for main group thermochemistry, thermochemical kinetics, noncovalent interactions, excited states, and transition elements: two new functionals and systematic testing of four M06-class functionals and 12 other functionals. Theor. Chem. Account. $120,215-241(2008)$.

26. Zhao, Y., Truhlar D.G. Density functionals with broad applicability in chemistry. Acc. Chem. Res. 41,157-167(2008).

27. Grimme, S. et al. Effect of the damping function in dispersion corrected density functional theory. J Comput. Chem. 32,1456-1465(2011). 
28. Burns, L. A. et al. Density-functional approaches to noncovalent interactions: A comparison of dispersion corrections (DFT-D), exchange-hole dipole moment (XDM) theory, and specialized functionals. J. Chem. Phys. 134,084107-084125(2011).

29. Vasiliou, A. K. et al. Modeling oil shale pyrolysis: high-temperature unimolecular decomposition pathways for thiophene. J. Phys. Chem. A. 121,7655-7666(2017).

30. Huang, X. et al. A Density Functional Theory study on pyrolysis mechanism of lignin in hydrogen plasma. Ind. Eng. Chem. Res 52,14107-14115(2013).

31. Johnson E. R. et al. Revealing noncovalent interactions. J Am Chem Soc $132,6498-6506(2010)$.

32. Lu, T., Chen F. Multiwfn: A multifunctional wavefunction analyzer. J. Comput. Chem. 33,580-592(2012).

33. Humphrey, W. et al. VMD: Visual molecular dynamics. J. Mol. Graphics. 14,33-38(1996).

34. Canneaux, S., Bohr, F., Henon, E. Kisthelp: a program to predict thermodynamic properties and rate constants from quantum chemistry results. J. Comput. Chem.

35. 35,82-93(2014).

36. Vernon, L. W. Free radical chemistry of coal liquefaction: role of molecular hydrogen. Fuel. 59:102-106(1980).

37. Zhai, Y. H. et al. Effects of water vapor and temperature on $\mathrm{NOx}$ and $\mathrm{CO}$ emissions during converter gas combustion. Fuel. 256,1-6(2019). 
367

368

369

370

371

372

373

38. Kozlowski, M. XPS study of reductively and non-reductively modifed coals. Fuel. $83,259-265(2004)$

39. Gerald, J. et al. Hydrogen Sulfide Formation Over Automotive Oxidation Catalysts. JSTOR. 84,750002-223, pp.477-484(1975).

40. Luo, Q. et al. Experimental Study of Gaseous Sulfur Species Formation during the Steam Hydrogasification of Coal. Energy Fuels. 28,3399-3402(2014).

41. Eyring, H. et al. Basic chemical kinetics [M], Wiley, (1980). 


\section{Figures}

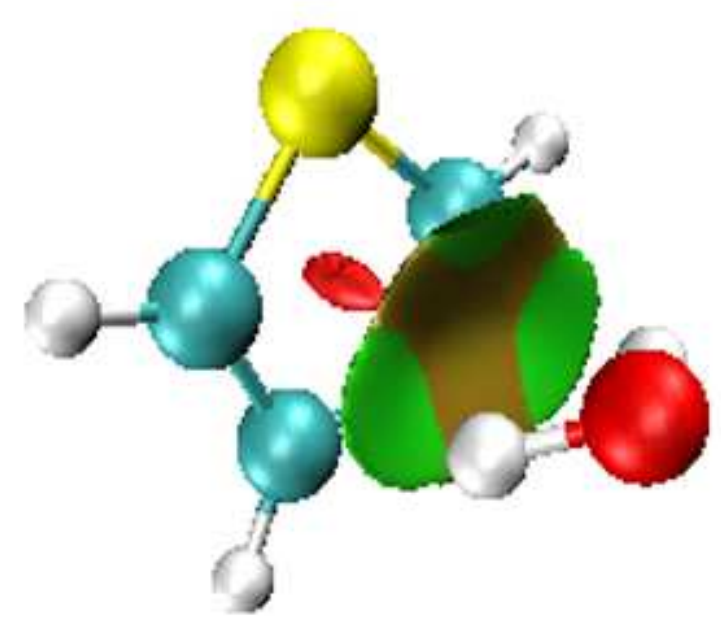

A

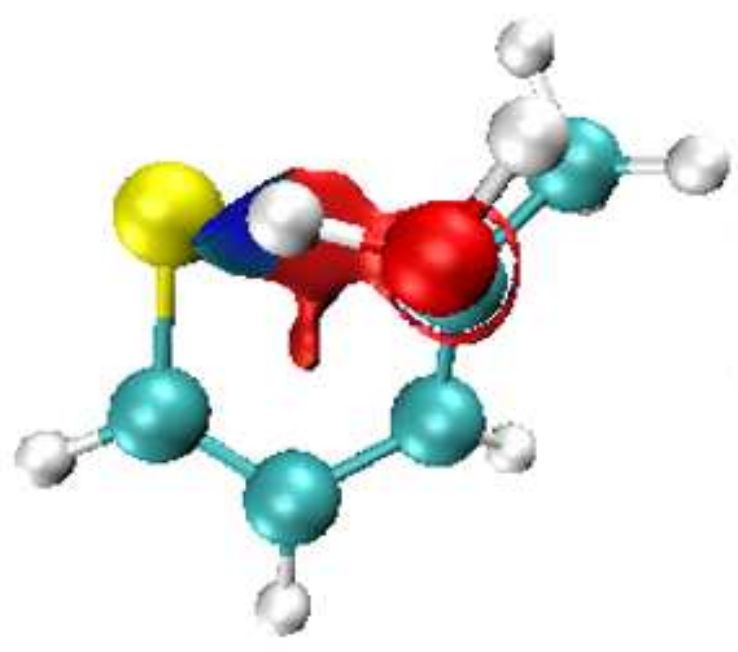

B
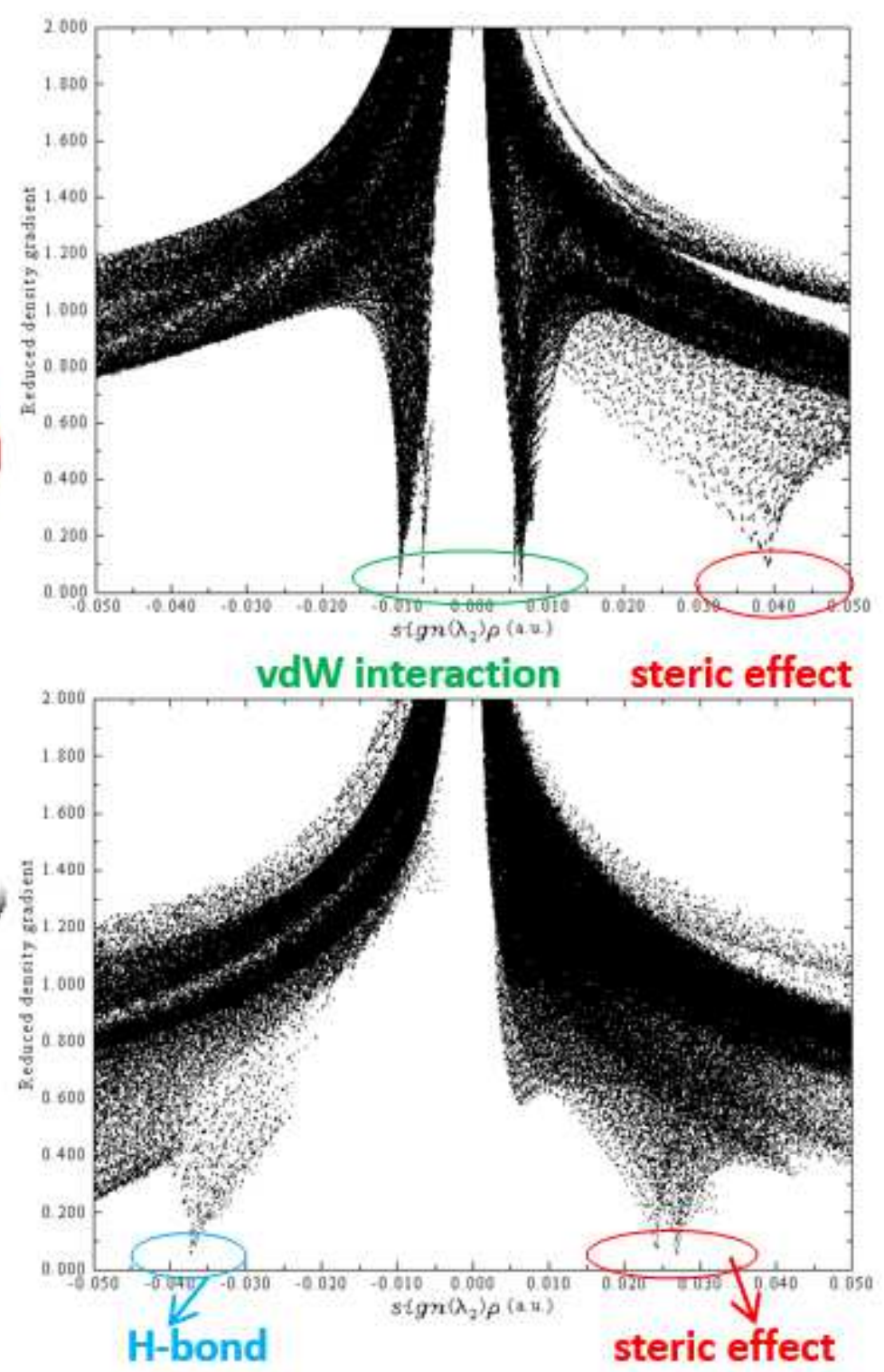

\section{Figure 1}

The RDG diagrams of complexes (i.e., complex Aand B) formed by two typical thiophene sulfurs with $\mathrm{H} 2 \mathrm{O}$ (complex $\mathrm{A}$ is about the complex of thiophene and mono-H2O; complex $\mathrm{B}$ is about the complex of mono-H2O and 2-methyl thiophene.) 


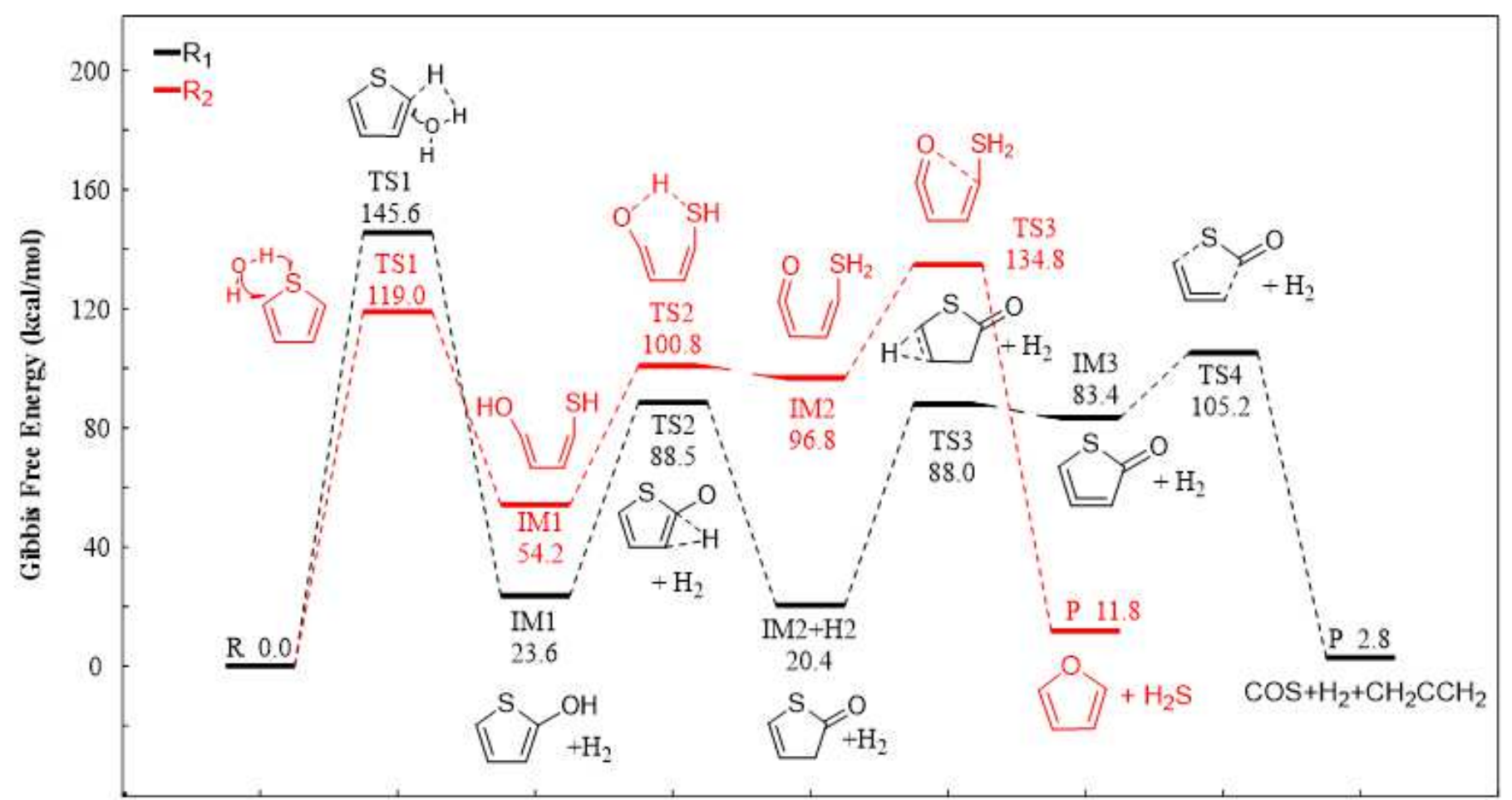

Figure 2

The energy diagram of thiophene and mono-H2O forming COS (R1) and H2S (R2) at 1200K

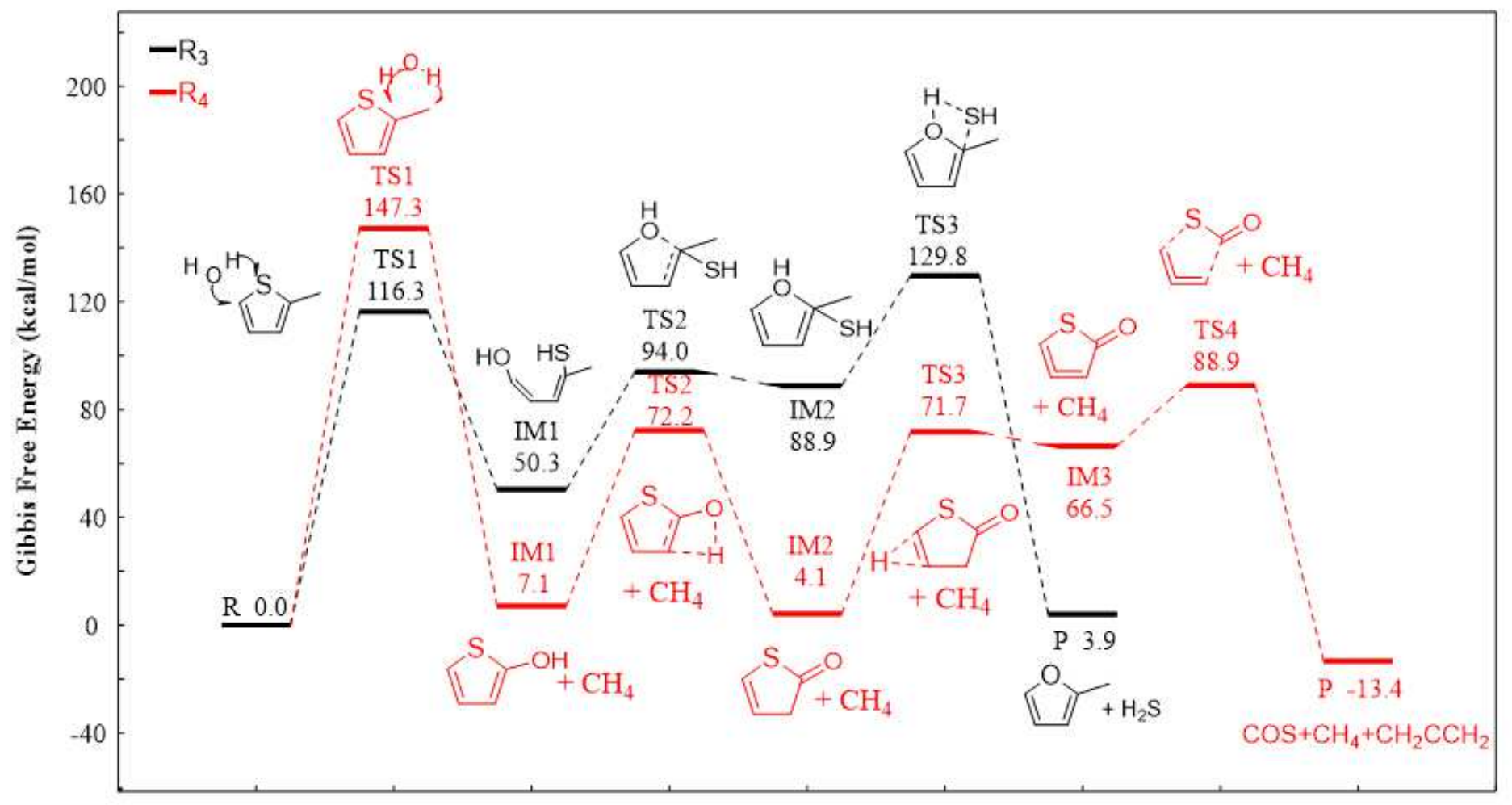

Figure 3 
The energy diagram of 2-methyl thiophene and mono-H2O forming H2S (R3) and COS (R4) at 1200K.

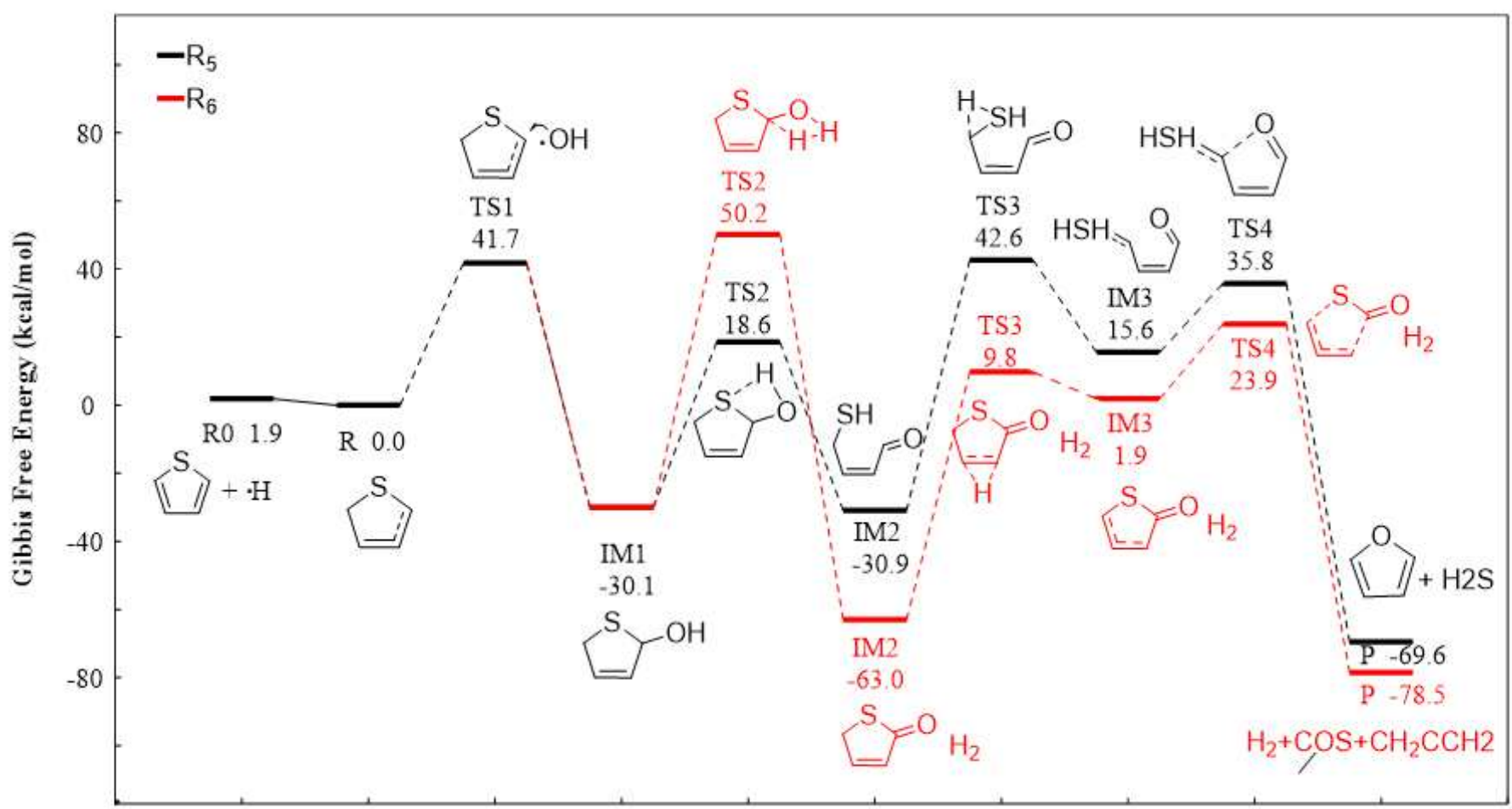

\section{Figure 4}

The energy diagram of thiophene and free radicals forming H2S (R5) and COS (R6) at $1200 \mathrm{~K}$

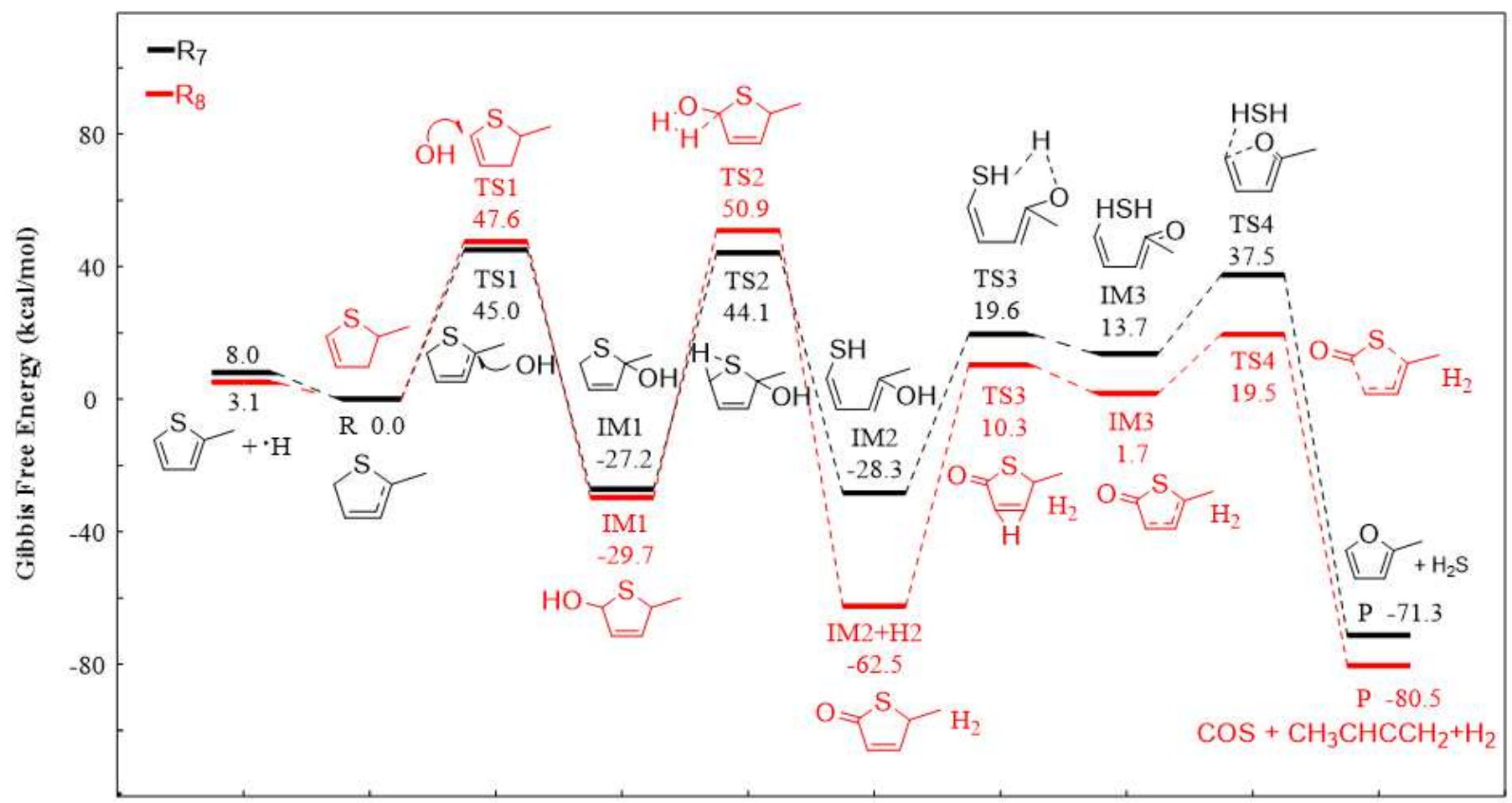

Figure 5 
The energy diagram of 2-methyl thiophene and free radicals forming H2S (R7) and COS (R8) at $1200 \mathrm{~K}$ 